\title{
Effect of Temperature on the Intensity of Basic Tastes: Sweet, Salty and Sour
}

\author{
Keri Lipscomb ${ }^{1}$, James Rieck ${ }^{1} \&$ Paul Dawson ${ }^{1}$ \\ ${ }^{1}$ Food, Nutrition and Packaging Sciences, Clemson University, United States \\ Correspondence: Paul Dawson, Food, Nutrition and Packaging Sciences, Clemson University, United States. \\ E-mail: pdawson@clemson.edu
}

Received: January 27, 2016

Accepted: May 19, 2016 Online Published: June 27, 2016

doi:10.5539/jfr.v5n4p1

URL: http://dx.doi.org/10.5539/jfr.v5n4p1

\begin{abstract}
Sensory panels were trained to identify specific concentrations of sucrose, sodium chloride and citric acid as an intensity level value of 6 on a 15-point scale for flavors of sweet, salty and sour, respectively. Trained panels were exposed to a single concentration of each taste singly, in combinations of 2 and all three at 3 temperatures $\left(3^{\circ} \mathrm{C}, 23^{\circ} \mathrm{C}, 60^{\circ} \mathrm{C}\right)$ using concentrations previously identified at an intensity level of 6 . Panelists determined the perceived intensity of each taste at each temperature in the single and combined treatments. Sweetness was perceived as more intense at $60^{\circ} \mathrm{C}$ than $23^{\circ} \mathrm{C}$ and $3{ }^{\circ} \mathrm{C}$ when tasted alone but not when in combination with other tastes (salty and sour). Salty perceived intensity was not affected by serving temperature while sourness was perceived as more intense at $23^{\circ} \mathrm{C}$ compared to $3^{\circ} \mathrm{C}$ and $60^{\circ} \mathrm{C}$. In general, perceived sweetness was less suppressed when combined with other tastes than salty and sour.
\end{abstract}

Keywords: taste intensity, basic tastes, sweet, sour, salty, temperature effect

\section{Introduction}

Scientists have been curious about the effect of temperature on basic tastes for many years (Hahn \& Gunther, 1932). Food is often prepared at one temperature but served and eaten at another. Sweet, sour, salty, and bitter have been considered primary tastes for many years (Meilgaard, 2007), although recently some have proposed a fifth basic taste called umami or savory (Johnson \& Wales University, 2003). This study focuses on just three of these tastes: sweet, sour, and salty. Several studies have evaluated the influence of temperature on varying concentrations of a basic taste solution to determine threshold values or perceived intensity, but none have reported using a single concentration with varying temperatures (Calvino, 1986; Pangborn et al., 1970; Paulus \& Reisch, 1980).

Bartoshul et al. (1982) evaluated 7 sucrose concentrations served at 4, 12, 20, 28, 36 and $44^{\circ} \mathrm{C}$ and concluded that the perceived sweetness of sucrose was more affected by higher temperature at lower sucrose concentrations and temperature effects on perceived intensity became negligible as sucrose concentration approached $0.5 \mathrm{M}$. Calvino (1986) reported similar results testing sucrose concentrations of 0 091-1.462 $\mathrm{M}$ at temperatures of 7, 37 and $50^{\circ} \mathrm{C}$ with sweetness being more intense at the higher serving temperature for the lower concentrations while this effect disappeared at about $0.4-0.5 \mathrm{M}$ sucrose concentrations. Schiffman et al. (2000) further verified the higher perceived intensity of sucrose served at higher temperatures with an all female panel using 6,22 and $50^{\circ} \mathrm{C}$ serving temperatures and sucrose concentrations of 2.5, 5, 7.5 and 10\% sucrose. Schiffman et al. (2000) also tested glucose, fructose, three terpenoid sweeteners, mannitol, sorbitol, alitame, aspartame, acesulfame-K, saccharin, cyclamate, thaumatin, dihydrochalcone and sucralose concluding that serving temperature had little effect on perceived intensity.

No effect of temperatures on salty perception was reported by Pangborn et al. (1970) using temperatures of 0,22 , 37 and $55^{\circ} \mathrm{C}$ and sodium chloride concentrations of $0.04,0.08,0.16,0.24,0.32,0.40,0.52$ and $0.64 \%$ and these researchers reported a linear increase for perceived intensity in this range of sodium chloride concentrations. McBurney et al. (1973) reported that sodium chloride was perceived as more intense at 17,37 and $42^{\circ} \mathrm{C}$ compared to intermediate serving temperatures of 22,27 and $32^{\circ} \mathrm{C}$, respectively. However in this study one temperature was served per day which may have compromised the results relative to serving temperature effects. Citric acid taste threshold level was highest at $2^{\circ} \mathrm{C}$ and lowest at $20.5^{\circ} \mathrm{C}$ with $41^{\circ} \mathrm{C}$ in between for threshold level (Powers et al., 1971). 
Paulus and Reisch (1980) studied the effect of temperature on sweet, salt, sour and bitter. The solutions for the determination of recognition thresholds were $0.5,1.0,2.0,4.0,8.0$ and 16 grams of sucrose, $0.093,0.185,0.375$, $0.75,1.5$ and 3.0 grams of $\mathrm{NaCl}$, and $0.031,0.062,0.125,0.25,0.5$ and 1.0 grams of citric acid to 1 liter of distilled water for sweet, salty and sour, respectively. Each taste was sampled at $10,20,40$ and $60^{\circ} \mathrm{C}$. The recognition threshold for sucrose was the lowest at 20 and $40^{\circ} \mathrm{C}$, increased at $60^{\circ} \mathrm{C}$ and $10^{\circ} \mathrm{C}$. For $\mathrm{NaCl}$, there was an in recognition threshold between 10 and $20^{\circ} \mathrm{C}$, a more pronounced increase at $40^{\circ} \mathrm{C}$, and no information reported at $60^{\circ} \mathrm{C}$. With citric acid the threshold increased between 10 and $20^{\circ} \mathrm{C}$, and decreased at $40^{\circ} \mathrm{C}$ to nearly the same threshold value found at $10^{\circ} \mathrm{C}$. Interestingly, Green et al. (1988) observed that the sweetness of saccharin was not affected by temperature $\left(36 \mathrm{vs} 20^{\circ} \mathrm{C}\right)$ while glucose, fructose and aspartame were perceived as more intense at the higher temperature.

Previous studies using two tastes found bitterness can be suppressed both by sweet tastes (Lawless, 1979; Kroeze \& Bartoshuk, 1985; Calvino et al., 1993; Frijters \& Schifferstein, 1994) and by sodium salts (Brelsin \& Beauchamp, 1995; Green, 2003), and that sweetness can suppress both sourness (Schifferstein \& Fritjer, 1991; Frank \& Archambo, 1986) and saltiness (Kroeze, 1978; Panghorn, 1962). Studies have also shown that sweetness can be suppressed by tastes that evoke bitterness (Calvino et al., 1990), saltiness (Kroeze, 1979) or sourness (Bonnans \& Noble, 1993). Pangborn (1962) reported that combining sucrose with sodium chloride suppressed salty perception while the perceived intensity of sweetness was enhanced by the addition of sodium chloride. Both Pangborn (1961) and Mcbride \& Finlay (1990) reported that combining sucrose and citric acid suppressed the intensity of sucrose while Schifferstein and Frijters (1990) found that combining sucrose and citric acid suppressed both sweet and sour intensities. Pangborn and Trabue (1967) looked at the interaction of salt-acid mixtures: $\mathrm{NaCl}-0.05,0.15,0.45$ and $1.35 \%$ and citric acid- $0.005,0.0125,0.0313$ and $0.078 \%$, served at $20^{\circ} \mathrm{C}$. In solution it was found that higher concentrations of citric acid suppressed saltiness while the lower concentrations enhanced saltiness. However, $\mathrm{NaCl}$ had an overall suppression effect on the perceived sourness of citric acid. In another study combining citric acid and sodium chloride, Wise and Breslin (2011) found that $\mathrm{NaCl}$ suppressed the perceived intensity of citric acid when compared to the perceived intensity of the same concentrations of citric acid without $\mathrm{NaCl}$.

No published studies have focused on the effect of temperature on the interrelationship of basic tastes when tastes are combined, though information on basic taste interrelationships is available. Green et al. (2010) evaluated the predominance of sweetness in combination with other tastes at 2 different temperatures however the objective was to determine if the intensity of sweetness was affected by the difference in temperature and not on how temperature impacted the intensity of all tastes singly and in combination. Therefore, the objective of this research was to determine the effect of serving temperature on the perceived intensity of basic tastes (sweet, salty, or sour) singly and in combination when all tastes were held at a single intensity level.

\section{Material and Methods}

\subsection{Test Solution Preparation}

Test solutions were prepared from food grade solutes of sucrose (Wal-Mart Private Label, Wal-Mart Stores, Inc., Bentonville, AK), sodium chloride (salt without iodine, Wal-Mart Private Label, Wal-Mart Stores, Inc., Bentonville, $\mathrm{AK}$ ), ) and citric acid $\left(\mathrm{NOW}^{\circledR}\right.$ Foods, Bloomington, IL) and water (Diamond Springs Water, Richmond, VA, U.S.A.). Screening solutions for the Basic Taste Acuity and Intensity Ranking Tests were prepared using the concentrations outlined by Wheeler et al. (1981). Solutions used during training were prepared using the concentrations provided in the Basic Taste Intensity Level Spreadsheet (Table 1). This spreadsheet was created based on standards of percentages for certain basic taste intensity levels in Sensory Evaluation Techniques (Meilgarrd et al., 2007). Solutions were prepared at least 12 hours before the day of use to allow ample time to equilibrate. The solutions were not kept in excess of 96 hours. Solutions were stored in Ball $^{\circledR}$ glass mason jars with plastic screw top lids (Jarden Home Brands, Daleville, IN, U.S.A.) and refrigerated when not in use. The day of screening, solutions were removed from the refrigerator and allowed to equilibrate to $23^{\circ} \mathrm{C}$ before distribution. The temperature of one sample was measured using a thermocouple and a sample equilibrium took approximately 30 minutes. 
Table 1 . Basic taste intensity levels and ingredient weights added to 1 liter of water needed to achieve each intensity level

\begin{tabular}{lllllllllllllllll}
\hline & \multicolumn{10}{c}{ Intensity Level } \\
\cline { 2 - 13 } Ingredient & 1 & 2 & 3 & 4 & 5 & 6 & 7 & 8 & 9 & 10 & 11 & 12 & 13 & 14 & 15 \\
\hline Sucrose & $10 \mathrm{~g}$ & $20 \mathrm{~g}$ & $30 \mathrm{~g}$ & $40 \mathrm{~g}$ & $50 \mathrm{~g}$ & $60 \mathrm{~g}$ & $70 \mathrm{~g}$ & $80 \mathrm{~g}$ & $90 \mathrm{~g}$ & $100 \mathrm{~g}$ & $112 \mathrm{~g}$ & $124 \mathrm{~g}$ & $136 \mathrm{~g}$ & $148 \mathrm{~g}$ & $160 \mathrm{~g}$ \\
Citric Acid & $0.4 \mathrm{~g}$ & $0.5 \mathrm{~g}$ & $0.6 \mathrm{~g}$ & $0.7 \mathrm{~g}$ & $0.8 \mathrm{~g}$ & $0.94 \mathrm{~g}$ & $1.08 \mathrm{~g}$ & $1.22 \mathrm{~g}$ & $1.36 \mathrm{~g}$ & $1.5 \mathrm{~g}$ & $1.6 \mathrm{~g}$ & $1.7 \mathrm{~g}$ & $1.8 \mathrm{~g}$ & $1.9 \mathrm{~g}$ & $2.0 \mathrm{~g}$ \\
$\begin{array}{l}\text { Sodium } \\
\text { Chloride }\end{array}$ & $0.4 \mathrm{~g}$ & $1.5 \mathrm{~g}$ & $2.3 \mathrm{~g}$ & $2.9 \mathrm{~g}$ & $3.5 \mathrm{~g}$ & $3.92 \mathrm{~g}$ & $4.34 \mathrm{~g}$ & $4.76 \mathrm{~g}$ & $5.15 \mathrm{~g}$ & $5.45 \mathrm{~g}$ & $5.75 \mathrm{~g}$ & $6.05 \mathrm{~g}$ & $6.35 \mathrm{~g}$ & $6.65 \mathrm{~g}$ & $7.0 \mathrm{~g}$ \\
\hline
\end{tabular}

\subsection{Panelist Recruitment and Training}

Subjects recruited for the study were ages 18 to 65 in good health, i.e. no individuals with diabetes, hypoglycemia, hypertension, dentures, chronic colds or sinusitis. Subjects were recruited by email and through personal communication. Twenty individuals, 14 female and 6 male, meeting the age and health requirements, completed the screening process before proceeding to training. A University Institutional Review Board approved all panels. After completing a screening questionnaire and meeting minimum requirements for participation in the panels, subjects completed a Basic Taste Recognition Test, an Intensity Ranking of Basic Taste Evaluation, an Exercise in Taste Scaling, then both a Triangle Test to determine if subjects could distinguish between intensities 5 and 6 and an Intensity Ranking Training before data collection commenced. Retention testing was also performed throughout the duration of the basic taste training to determine if panelists were retaining the ability to distinguish between intensity levels. . For example, during salty training a sweet reference and unknown samples were given in addition to the day's salty samples on days 6 and 8 . The reference and samples were not identified as sweet, only labeled as REF for reference and 3-digit code numbers for the samples. Throughout sour basic training a salty reference and unknown samples were provided along with the sour samples on day 6 with no prior notice to the subjects. Using the same retention method, a sweet reference and unknown samples were incorporated into the training on day 7 of sour training. A total of 40 hours of training were completed including basic taste acuity testing and screening.

\subsection{Facilities and Ballot}

The sensory lab consists of 6 privacy booths equipped with Dell Mini P787J notebook computers (Dell, Santa Clara, CA, U.S.A.) on which computerized ballots recorded subject's evaluation of the samples. Each booth also contained bottled water, cups, napkins and expectorant cups. Results were recorded using SIMS 2000 Sensory Evaluation Testing Software (Sensory Computer Systems, Morristown, NJ, U.S.A.). DELETED SENTENCE. In addition to providing scales to record results, the sensory ballots clearly outlined the instructions for evaluating samples and the objectives of the study before the subjects received samples

The sensory evaluation samples were served at 3 temperatures $\left(3,23,60^{\circ} \mathrm{C}\right)$ with $30 \mathrm{ml}$ being dispensed in 118 $\mathrm{ml}(4 \mathrm{oz})$ plastic cups with lids (Solo ${ }^{\circledR}$ Cup Co., Urbana, IL, U.S.A.) affixed with predetermined 3-digit code numbers corresponding to the basic taste concentration using a dispenser (Cole Palmer, U.S.A.). After dispensing, room temperature samples and references were held until they equilibrated to room temperature. Cold samples $\left(3^{\circ} \mathrm{C}\right)$ placed in refrigeration until they equilibrated after which they were presented individually to panelists. $60^{\circ} \mathrm{C}$ samples were held in a Ball ${ }^{\mathbb{B}}$ Mason jar fitted with the dispenser (Cole Palmer, U.S.A.). The jar was then placed in an 18 liter (4.75 gallon) clear plastic water bath (Cambro ${ }^{\circledR}$ Manufacturing Co., Huntington Beach, CA, USA) fitted with a Sous Vide Immersion Circulator (PolyScience, Niles, IL, USA) set to $60^{\circ} \mathrm{C}$. Thirty $\mathrm{mL}$ of the hot solution were dispensed into a $4 \mathrm{oz}$ Styrofoam portion cup with a vented lid (Dart ${ }^{\mathbb{B}}$ Container Corp., Mason, MI, U.S.A.) for each individual subject immediately before distribution. All temperatures were verified with a $-20 \sim 110^{\circ} \mathrm{C}$ mercury thermometer (Barker Diagnostics Inc., Deerfield, IL, U.S.A.).

When building each sensory ballot in the SIMS 2000 software, a rotation plan was automatically created. Each ballot was constructed so that a subject was required to log into the computerized ballot with their panelist number to activate the test. One sample set from the rotation plan was written on a note card and given to a subject when they entered a privacy booth. Subjects were provided with a tray of all reference samples (room temperature) and unsalted crackers upon entry to a booth. The note cards only provided code numbers and gave no indication of the order of sample presentation. 


\subsection{Selection of Single Intensity Level}

Before training began, a preliminary test was performed to determine which single intensity level would be used during sensory evaluations. Subjects participating in the preliminary tests tasted sucrose solutions of intensities 5 through 10. The subjects were asked to taste each intensity level, between which they were instructed to eat a portion of an unsalted cracker and drink bottled water before moving on to another sample. During a round table discussion, subjects indicated intensity levels 6,7 , and 8 to be the most palatable of the sweet solutions. Upon further questioning, some of the subjects expressed difficultly differentiating between intensities 7 and 8 . All subjects verbalized they were able to detect a difference between the samples of intensity levels 6 and 7 . Considering this feedback, intensity level 6 was chosen as the single intensity level for use during all sensory evaluations in this study.

\subsection{Sensory Evaluation}

Of the 20 subjects participating in the sensory evaluations, there were 14 females and 6 males, with a combined mean age of 27. All were non-smokers who completed the necessary screening procedures and at least $80 \%$ of training for each basic taste. One subject was unavailable for all 10 days of salty basic taste training, but completed $100 \%$ of the required training for sweet and sour. This subject was excluded from any sensory evaluation containing salt.

Each basic taste and combination test was replicated three times for a total of 21 sensory panels. The order of the sensory panels was randomized using SAS ${ }^{\circledR} 9.2$ Business Analytics Software (SAS ${ }^{\circledR}$ Institute Inc., Cary, NC, U.S.A.). Panels were scheduled over 4 weeks with panels occurring twice daily with a target time of 11:00 A.M. and 2:00 P.M. Subjects were allowed to schedule specific panel times if unable to participate at the target times. Eight subjects of the total 20 cleared to participate, were used for each panel. A total of 16 subjects were used each day, with 4 panelists available as backup if a scheduled subject could not participate.

\subsection{Statistical Analysis}

An analysis of variance (ANOVA) was used to determine any significant effects of serving temperature on intensity perception. When serving temperature was found to have a significant effect $(p \leq 0.05)$ on perceived intensity, least square mean (LSM) $p$-values $(\mathrm{p} \leq 0.05)$ were used to determine which serving temperatures differed in perceived intensity. Standard errors of mean intensity were also determined. The ANOVA, LSM and standard error results for basic tastes and basic taste combinations were performed using SAS $^{\circledR} 9.2$ Business Analytics Software.

\section{Results}

\subsection{Single Basic Tastes}

Serving temperature had a significant effect $(\mathrm{p}=0.0005)$ on perceived intensity of sweet taste with the $60^{\circ} \mathrm{C}$ serving temperature perceived as more intense than when sweet taste at the same sucrose concentration was served at room temperature and cold $\left(3^{\circ} \mathrm{C}\right)($ Table 2$)$.

However, there was insufficient evidence to conclude temperature influenced the perceived saltiness of $\mathrm{NaCl}$ solutions $(p=0.7746)$ (Table 2). While temperature did not affect the perceived saltiness of the samples, it is interesting to note the standard error of the $23^{\circ} \mathrm{C}$ sample means was the lowest of the 3 samples, and therefore the individual estimations by the subjects were closer to the mean intensity. Furthermore, all serving temperatures were very close to the actual intensity of 6 , thus temperature had little influence on perceived saltiness.

Similar to sweet taste, serving temperature had a significant effect on the perceived intensity of sour taste $(p=0.0007)$ with the hot and cold serving temperatures being perceived as less sour than samples served at room temperature. With sour taste, the room temperature sample was perceived as more intense (7.0) than the reference (6.0) possibly due to the relative perception of the other temperature samples during testing.

Table 2. Perceived intensity ( 1 to 15 scale) of sweet, salty and sour tastes, (and standard errors) served singly at three different temperatures

\begin{tabular}{llll}
\hline Temperature & Sweet taste & Salty taste & Sour taste \\
\hline $60^{\circ} \mathrm{C}$ & $8.6^{\mathrm{a}}(0.49)$ & $6.3(0.57)$ & $5.6^{\mathrm{b}}(0.43)$ \\
$23^{\circ} \mathrm{C}$ & $7.3^{\mathrm{b}}(0.41)$ & $5.7(0.35)$ & $7.0^{\mathrm{a}}(0.33)$ \\
$3^{\circ} \mathrm{C}$ & $6.8^{\mathrm{b}}(0.47)$ & $6.2(0.69)$ & $4.5^{\mathrm{b}}(0.53)$ \\
\hline
\end{tabular}

${ }^{\mathrm{ab}}$ means within the same column with different superscripts are significantly different $(\mathrm{p} \leq 0.05)$. $(\mathrm{n}=20)$. 


\subsection{Sweet/Salty Combination}

When sweet and salty tastes were served together, there was as significant effect due to temperature on sweetness $(\mathrm{p}=0.039)$ but not on saltiness $(\mathrm{p}=0.816)$ (Table 3$)$. When served with salty taste, sweetness was more intense when served hot $(\mathrm{p}=0.0089)$ and when served at room temperature $(\mathrm{p}=0.0017)$ compared to when served cold. This differed from when sweet taste was served alone when the hot serving temperature was more intense than both room and cold serving temperatures. Also, the overall perceived intensity of both sweet and salty were lower when the tastes were served together than when served singly.

Table 3. Perceived intensity (1 to 15 scale) and standard errors for sweet, salty and sour tastes served in paired combinations at three different temperatures

\begin{tabular}{|c|c|c|}
\hline \multirow[b]{2}{*}{ Temperature } & \multicolumn{2}{|c|}{ Sweet and salty tastes together } \\
\hline & Sweet taste & Salty taste \\
\hline $60^{\circ} \mathrm{C}$ & $5.6^{\mathrm{a}}(0.41)$ & $3.3(0.51)$ \\
\hline $23^{\circ} \mathrm{C}$ & $5.9^{\mathrm{b}}(0.37)$ & $3.6(0.43)$ \\
\hline \multirow[t]{3}{*}{$3^{\circ} \mathrm{C}$} & $4.4^{\mathrm{b}}(0.37)$ & $3.7(0.37)$ \\
\hline & \multicolumn{2}{|c|}{ Sweet and sour tastes together } \\
\hline & Sweet taste & Sour taste \\
\hline $60^{\circ} \mathrm{C}$ & $5.1^{\mathrm{a}}(0.51)$ & $4.8(0.55)$ \\
\hline $23^{\circ} \mathrm{C}$ & $4.7^{\mathrm{ab}}(0.41)$ & $4.2(0.53)$ \\
\hline \multirow[t]{3}{*}{$3^{\circ} \mathrm{C}$} & $3.5^{\mathrm{b}}(0.41)$ & $3.5(0.53)$ \\
\hline & \multicolumn{2}{|c|}{ Salty and sour tastes together } \\
\hline & Salty taste & Sour taste \\
\hline $60^{\circ} \mathrm{C}$ & $4.5^{\mathrm{a}}(0.49)$ & $5.0(0.53)$ \\
\hline $23^{\circ} \mathrm{C}$ & $3.3^{\mathrm{b}}(0.45)$ & $5.3(0.47)$ \\
\hline $3^{\circ} \mathrm{C}$ & $3.3^{\mathrm{b}}(0.51)$ & $4.5(0.41)$ \\
\hline
\end{tabular}

${ }^{\mathrm{ab}}$ means with different superscripts are significantly different $(\mathrm{p} \leq 0.05)$.

$(\mathrm{n}=24)$.

\subsection{Sweet/Sour Combination}

The results of the sweet/sour combination were very similar to those of the sweet/salty combination in that serving temperature did affect $(\mathrm{p}=0.033)$ perceived sweetness but did not affect perceived sourness (0.079) (Table 3$)$. Also, like the sweet/salty combination, both hot $(\mathrm{p}=0.012)$ and room $(\mathrm{p}=0.0118)$ serving temperatures were perceived to be more intense than the cold serving temperature. A significant difference was not found between the hot and room temperature means $(\mathrm{p}=0.4126)$.

\subsection{Sour/Salty Combination}

For the sour/salty taste combination, salty taste intensity was affected $(\mathrm{p}=0.045)$ by serving temperature while sour was not (Table 3). Salt served at room g temperature y was perceived as more intense compared to when it was served cold $(\mathrm{p}=0.034)$ and hot $(\mathrm{p}=0.266)$. This perception differed from when salty was served alone where no difference in perceived intensity was found. As with the previous combinations, overall intensity for both taste were lower than when the tastes were served alone. While the sour intensity was not significantly affected by temperature, it was ranked as more intense than the salty taste.. In single evaluations, citric acid in solution produced a statistical difference due to temperature, whereas the single $\mathrm{NaCl}$ evaluations did not.

\subsection{Sour/Sweet/Salty Three-way Combination}

The sour portion of the three-way combination provided the only significant a $\mathrm{p}$-value $(\mathrm{p}=0.0455)$ of the trio (Table 4). The mean sour intensity was different between cold and hot, and cold and room temperature were not detectable. The temperature effect between the hot and room temperature means provided a verifiable difference due to temperature $(\mathrm{p}=0.0188)$. 
No research was found on the interaction of three of these basic tastes in combination using a temperature treatment or otherwise. As with all combinations involving sucrose in this study, sweetness was the dominant taste in that it lessened the perceived intensity of sour and salty tastes. The perceived intensity of sucrose also increased with temperature, as seen when sweet was evaluated alone, the sweet/sour combination and to a slightly lesser degree, the sweet/salty panels. The difference in intensity estimates between citric acid and sucrose appear more pronounced when combined with $\mathrm{NaCl}$, then when evaluated without. In the trio combination, sour was estimated as more intense than salty at 3 and $60^{\circ} \mathrm{C}$ but not at $23^{\circ} \mathrm{C}$. However, when the two were paired, sour had a higher mean across all temperatures. The mean intensities of sour and salty were estimated to be very close at the two lower temperatures. The largest difference in perceived intensity between the two was observed at $60^{\circ} \mathrm{C}$.

Table 4. Perceived intensity and standard errors for sour/sweet/salty basic tastes for sour/sweet/salty basic taste evaluations

\begin{tabular}{lcc}
\hline \multicolumn{3}{c}{ Sour Basic Taste } \\
\hline \multicolumn{1}{c}{ Temperature } & Mean Estimated Intensity & Standard Error \\
\hline $60^{\circ} \mathrm{C}^{\mathrm{a}}$ & $2.8^{\mathrm{b}}$ & 0.47 \\
$23^{\circ} \mathrm{C}$ & $4.0^{\mathrm{a}}$ & 0.49 \\
$3{ }^{\circ} \mathrm{C}$ & $3.0^{\mathrm{b}}$ & 0.51 \\
\hline \multicolumn{3}{c}{ Sweet Basic Taste } \\
\hline $60^{\circ} \mathrm{C}$ & 5.1 & 0.39 \\
$23^{\circ} \mathrm{C}$ & 5.3 & 0.63 \\
$3{ }^{\circ} \mathrm{C}$ & 4.1 & 0.47 \\
\hline \multicolumn{3}{c}{} \\
\hline $60^{\circ} \mathrm{C}$ & Salty Basic Taste \\
$23^{\circ} \mathrm{C}$ & 3.2 & 0.35 \\
$3{ }^{\circ} \mathrm{C}$ & 2.6 & 0.49 \\
\hline
\end{tabular}

${ }^{\mathrm{ab}}$ means with different superscripts are significantly different $(\mathrm{p} \leq 0.05)$.

$(n=24)$.

\section{Discussion}

\subsection{Sweet Basic Taste}

The basic taste results for sweet found as the sample temperature increased so did the perceived sweetness of the samples by the subjects. These results are concurrent with the findings of Baroshuk et al. (1981), Calvino (1983), Schiffman et al. (2000) and Talavera et al. (2005) that found a linear relationship between temperature and the perceived sweetness of sucrose solutions. However, a study by Paulus and Reisch (1980) indicated, at least with stimulus and recognition thresholds, that perceived intensity did not increase with an increase in sample temperature. They found intensity was lowest between 20 and $40^{\circ} \mathrm{C}$ and perceived at its highest at $60^{\circ} \mathrm{C}$. The sucrose intensities were higher at $10^{\circ} \mathrm{C}$ than the mid-range temperatures $\left(20\right.$ and $\left.40^{\circ} \mathrm{C}\right)$ but not significantly so. These results provide a nonlinear, almost $U$ shaped curve of the effect of temperature on stimulus and recognition thresholds. It is noteworthy to mention at this point that much of the research that will be discussed reporting conflicting results studied taste thresholds and not mid-range or optimal sensory levels as was done in the current study.

\subsection{Salty Basic Taste}

While the salty evaluation results are similar to the observations of Pangborn et al. (1970) that perceived intensity of sodium chloride solutions changed due to temperature, these results are not supported by some other works. A study by McBurney et al. (1973) established that the threshold for $\mathrm{NaCl}$ was higher at temperatures 4 and $42^{\circ} \mathrm{C}$ and lower at temperatures 22 to $32^{\circ} \mathrm{C}$, where they were also very close in range. In contrast, a 1932 study performed by Hahn and Gunther provided evidence that like the sucrose samples in the sweet evaluations, $\mathrm{NaCl}$ thresholds rose 
as the temperature increased. Hahn and Gunther's theory that perception of saltiness decreases as the temperature is increased is supported by a study almost 50 years later by Paulus and Reisch (1980).

The inability of the panel used in this study to distinguish a temperature effect between the three samples could be due to heightened $\mathrm{NaCl}$ sensitivity. Of the 20 individuals who participated in the salty sensory evaluations, $50 \%$ indicated on the Screening Questionnaire they felt their consumption of salty foods was not significant. Evidence generated from the results of a study observing how long-term reduction of sodium can alter one's taste of salt, indicates low intake over time, can increase the perceived intensity of salt in foods (Bertino, Beauchamp \& Engleman, 1982). It is reasonable to speculate that an individual who consumes a reduced amount of dietary sodium could perceive the salt in food as more intense than someone who consumes more sodium.

\subsection{Sour Basic Taste}

The results of the sour sensory evaluations are not supported by two other studies. In a study of the effect of temperature on the threshold values of several substances including citric acid, Powers et al. (1971), found the threshold of citric acid to be highest at $2^{\circ} \mathrm{C}$. Yet panelists found the citric acid threshold to be lower at 20.5 and $41^{\circ} \mathrm{C}$. In contrast, a study by Paulus and Reisch (1980) evaluating the effect of temperature on the stimulus and recognition thresholds of citric acid provided no statistically verifiable evidence that temperature had an effect on either threshold. However, the authors do mention that though not statistically significant, there was a tendency of the threshold to increase as the temperature increased.

\subsection{Sweet/Salty Combination}

Literature on the pairing of sweet/salty combinations provides little insight into the relationship between sucrose and $\mathrm{NaCl}$ combination solutions based on temperature, as the research previously conducted does not use temperature as a treatment. Pangborn (1962) found that the addition of sucrose suppressed saltiness at the three higher concentrations $(0.36,1.08$ and $3.24 \%)$ while no affect was found on saltiness at the lowest concentration $(0.12 \%)$. The perceived sweetness of the two lower sucrose concentrations $(0.75$ and $2.25 \%)$ was enhanced by the addition of $\mathrm{NaCl}$ at all three concentrations. However, the higher concentrations of sucrose (6.75 and 20.25\%) were suppressed by all concentrations of $\mathrm{NaCl}$. The $20.25 \%$ was suppressed the most, while $6.75 \%$ was only slightly suppressed. More research by Pangborn and Chrisp (1964) and Pangborn and Trabue (1964) on the interrelationship of sucrose and $\mathrm{NaCl}$ was performed using not only varying concentrations of tastes, but also evaluates the basic taste combinations in canned tomato juice and lima bean puree respectively. However, in an article on "Flavor effects of sodium chloride" by Gillette (1985), the author states that the perception of sweetness is amplified by the addition of salt. While it is evident the sweetness of the solution was rated as more intense by subjects than salty, the mean intensities of perceived sweetness were evaluated as less intense in combination than when evaluated singularly. The saltinessof the combination mimics the observations from the single salty panel in that change due to temperature is insignificant.

\subsection{Sweet/Sour Combination}

In a report by Horn (1981) on evaluating sweetness and the many factors that influence its perception, it was stated that acidic ingredients such as citric acid can somewhat suppress the sweetness of sucrose. The results of this evaluation appear to reinforce Horn's statement since the same intensity of sucrose solution was perceived as higher when evaluated alone, than when in combination with citric acid. The mean intensities for sweet and sour were estimated relatively close at all temperatures in combination, while the means for the sweet/salty combination were not as similar.

McBride and Finlay (1989, 1990), Pangborn (1961) and Schiffman et al. (2000) used varying concentrations of sucrose and citric acid in combination solutions, however none of the authors researched how temperature would influence the interrelationships. Pangborn (1961) reported for the single-sample presentation, all concentrations $(0.00,0.007,0.023$ and $0.073 \%)$ of citric acid suppressed the perceived intensity of sucrose at all concentrations $(0.5,1.8,5.8$ and $20.0 \%)$. The interpretation of the pair-sample presentation using the same concentrations above plus additional sucrose $(1.0,2.0,5.0,10.0$ and $20.0 \%)$ and citric acid $(0.00,0.005,0.010,0.020$ and $0.040 \%)$ concentrations provided a bit more insight. Citric acid suppressed the sweetness of sucrose at the lower concentrations than at the higher sucrose concentrations. McBride and Findlay (1990) found that when rating sweetness, only the highest concentration of citric acid (of $0.00,0.006$ or $0.05 \mathrm{M}$ ) suppressed the sweetness of sucrose. Similar results were found when subjects rated the acidity of the mixtures. The highest level of sucrose (of $0,0.172$ or $0.8 \mathrm{M}$ ) in the solution suppressed the acidity of citric acid indicating that sucrose and citric acid mixtures mutually suppressed one another depending on rating criteria. Schifferstein and Frijters (1990) conducted 3 investigations (total intensity, sweetness and sourness) consisting of various concentrations of both sucrose $(0.00,0.125,0.250,0.500$ and $1.000 \mathrm{M})$ and citric acid $(0.00,0.00125,0.0025,0.005,0.010 \mathrm{M})$. They 
found that the suppression of citric acid in solution was dependant on both the concentration of the citric acid and sucrose, while the sweetness suppression of sucrose was only dependant on the concentration of citric acid.

\subsection{Sour/Salty Combination}

Literature by Pangborn and Trabue (1967) and Wise and Breslin (2011), was based on the combination of varying concentrations of citric acid and salt and incorporated no temperature treatment. Pangborn and Trabue (1967) found that higher concentrations of citric acid (of 0.005, 0.0125, 0.0313 and $0.078 \%$ ) suppressed saltiness while the lower concentrations enhanced saltiness. However, $\mathrm{NaCl}$ had an overall suppression effect on the perceived sourness of citric acid. The higher concentrations of citric acid were suppressed the most with the two lowest concentrations showing a slight initial drop in perceived sourness. Wise and Breslin (2011) used citric acid concentrations of 1.67, 5 and $15 \mathrm{mM}$ and for $\mathrm{NaCl} 130,280$ and $500 \mathrm{mM}$ and concluded that the addition of $\mathrm{NaCl}$ suppressed the perceived intensity of citric acid when compared against the perceived intensity of the same concentrations of citric acid alone.

\subsection{Sweet/Salty/Sour Combination}

No research was found on the interaction of three of these basic tastes in combination using more than 2 temperatures. As with all combinations involving sucrose in this study, it was the dominant taste when in combination with other basic tastes. The perceived intensity of sucrose also increased with temperature, as seen in the single sweet panel, the sweet/sour combination and to a slightly lesser degree, the sweet/salty panels. The difference in intensity estimates between citric acid and sucrose appear more pronounced when combined with $\mathrm{NaCl}$, than when evaluated without $\mathrm{NaCl}$. In the trio combination, sour was estimated as more intense than salty at 3 and $60^{\circ} \mathrm{C}$ but not at $23^{\circ} \mathrm{C}$. However, when the two were paired, sour had a higher mean across all temperatures. The mean intensities of sour and salty were estimated to be very close at the two lower temperatures. The largest difference in perceived intensity between the two was observed at $60^{\circ} \mathrm{C}$.

Green (2010) reported that the intensity of binary, tertiary and quaternary mixtures of sucrose, citric acid, sodium chloride and quinine sulfate were additive and that sweetness (sucrose) was the dominant quality, being most resistant to suppression by other tastes and more likely to suppress other tastes. The role of sweetness and bitterness for food choices have been theorized to be related to survival and evolution of man to find high-energy foods (sweet) and avoid potentially poisonous foods (bitter) (Lawless, 1979; Kroese \& Bartoshuk, 1985; Gilan, 1982, 1984).

Temperature has been shown to affect perceived intensity of most single tastes. For instance, Bartoshuk et al. (1982) found that weak sucrose solutions $(<0.5 \mathrm{M})$ had an increase in perceived intensity with an increase in temperature but above $0.5 \mathrm{M}$ the temperature effect diminished. This finding was substantiated by Calvino (1986) who reported that cool sucrose solutions were judged less sweet than warmer solution up to the 0.4 to $0.5 \mathrm{M}$ concentration zone. Moskowitz (1973) estimated the sensing intensity between $25-50^{\circ} \mathrm{C}$ for glucose, $\mathrm{NaCl}$, citric acid and quinine sulfate and found that all except citric acid were unaffected by temperature. McBurney et al. (1973) reported that the taste thresholds for $\mathrm{NaCl}$ (salty), $\mathrm{HCl}$ (sour) and quinine sulfate (bitter) were lowest between 22 and $32^{\circ} \mathrm{C}$ and that thresholds rose above these temperatures in the test range of 17 to $42^{\circ} \mathrm{C}$. One study (Schiffman et al., 2000) contradicting temperature effects on sweetness in nearly all sweeteners commercially available was Schiffman et al. (2000).

The current study provided support of published information on the temperature/perceived intensity relationship when taste solutions were set at a single concentration and only temperature was altered. The primary findings of this study can be summarized as follows. Sweet and sour were perceived as more intense at $60^{\circ} \mathrm{C}$ and $23^{\circ} \mathrm{C}$, respectively, compared to the other two temperatures tested. When sweet/salty were tasted together, sweet intensity was less at $3^{\circ} \mathrm{C}$ compared to the other temperatures tested while temperature had no effect on salty perceived intensity. Ironically, the same temperature effect was seen for salty (lower at $3^{\circ} \mathrm{C}$ ) when combined with sour. For sweet/sour combinations sweet was perceived as more intense at $60^{\circ} \mathrm{C}$ compared to $3^{\circ} \mathrm{C}$. When all three basic tastes were combined, only sour produced a significant difference due to temperature.

Since significant effects for perceived intensity were found due to serving temperature and since combining basic tastes also affects perceived intensities, food formulations and serving temperatures are important factors to consider in the food and beverage industry.

\section{References}

Bartoshuk, L. M., Rennert, K., \& Stevens, J. C. (1982) Effects of temperature on the perceived sweetness of sucrose. Physiology and Behavior, 28, 905-910. http://dx.doi.org/10.1016/0031-9384(82)90212-8 
Bertino, M., Beauchamp, G. K., \& Engleman, K. (1982) Long-term reduction in dietary sodium alters the taste of salt. The American Journal of Clinical Nutrition, 36, 1134-1141.

Bonnans, S., \& Noble, A. C. (1993). Effect of sweetener type and of sweetener and acid levels on temporal perception of sweetness, sourness and fruitiness. Chemical Senses, 18, 273-283. http://dx.doi.org/10.1093/chemse/18.3.273

Breslin, P. A., \& Beauchamp, G. L. (1995). Suppression of bitterness by sodium: variation among bitter taste stimuli in humans. Physiology \& Behavior, 20, 609-623. http://dx.doi.org/10.1093/chemse/20.6.609

Calvino, A. M. (1986). Perception of sweetness: The effects of concentration and temperature. Physiology and Behavior, 36, 1021-1028. http://dx.doi.org/10.1016/0031-9384(86)90474-9

Calvino, A. M., GarciA-Medina M. R., \& Cometto-Muniz, J. E. (1990). Interactions in caffeine-sucrose and coffee-sucrose mixtures: evidence of taste and flavor suppression. Chemical Senses, 15, 505-519. http://dx.doi.org/10.1093/chemse/15.5.505

Calvino, A. M., Garcia-Medina, M. R., Cometto-Muniz, J. E., \& Rodriguez, M. B. (1993). Perception of sweetness and bitterness in different vehicles. Perception \& Pyschophysics, 54, 751-758. http://dx.doi.org/10.3758/BF03211799

Frank, R. A., \& Archambo, G. (1986). Intensity and hedonic judgments of tastemixtures. Perception \& Pyschophysics, 48, 326-330.

Frijter, J. E., \& Schifferstein, H. N. (1994). Perceptual interactions in mixtures containing bitter tasting substances. Physiology \& Behavior, 56, 1243-1249. http://dx.doi.org/10.1016/0031-9384(94)90372-7

Gilan, D. J. (1982). Mixture suppression: the effect of cooling on the perception of carbohydrate and $\mathrm{NaCl}$. Perception \& Pyschophysics, 32, 504-510.

Gilan, D. J. (1984). Evidence for peripheral and central processed in taste adaptation. Perception \& Pyschophysics, 35, 1-4. http://dx.doi.org/10.3758/BF03205918

Gilette, M. (1985). Flavor effects of sodium chloride. Food Technology, 39(6), 47-56.

Green, B. G. (2003). Studying taste as a cutaneous sense. Food Quality \& Preference, 14, 99-109. http://dx.doi.org/10.1016/S0950-3293(02)00071-X

Green, B. G., \& Frankman, S. P. (1988). The effect of cooling on the carbohydrate and intensive sweeteners. Physiology \& Behavior, 43(4), 515-519. http://dx.doi.org/10.1016/0031-9384(88)90127-8

Green, B. G., Lim, J., Osterhoof, F., Blacher, K., \& Nachtigal, D. (2010). Physiology \& Behavior, 101(5), 731-737. http://dx.doi.org/10.1016/j.physbeh.2010.08.013

Hahn, H., \& Gunther, H. (1932). Uber die reize und die reizbedingungen des geschmacksinnes. Pflugers Arch Ges. Physiol., 231, 48. http://dx.doi.org/10.1007/BF01754527

Horn, H. E. (1981). Evaluating sweetness: Many factors influence perception. Food Product Development, 15(4), 28.

Johnson \& Wales University. (2003). Culinary fundamentals. Thailand: Johnson \& Wales University.

Kroeze, J. H. (1978). The taste of sodium chloride: masking and adaption. Chemical Senses, 3, 43-449. http://dx.doi.org/10.1093/chemse/3.4.443

Kroeze, J. H. (1979). Masking and adaptation of sugar sweetness intensity. Physiology \& Behavior, 22, 347-351. http://dx.doi.org/10.1016/0031-9384(79)90097-0

Kroeze, J. H., \& Bartoshuk, L. M. (1985). Bitterness suppression as revealed by split-tongue taste stimulation in humans. Physiology \& Behavior, 35,779-783. http://dx.doi.org/10.1016/0031-9384(85)90412-3

Lawless, H. T. (1979). Evidence for neural inhibition in bittersweet taste mixture. J. Comp Perception \& Pyschophysics, 93, 538-547. http://dx.doi.org/10.1037/h0077582

McBride, R. L., \& Finlay, D. C. (1989). Perception of taste mixtures by experienced and novice assessors. Journal of Sensory Studies, 3, 237. http://dx.doi.org/10.1111/j.1745-459X.1989.tb00447.x

McBride, R. L., \& Finlay, D. C. (1990). Perceptual integration of tertiary taste mixtures. Perception \& Pyschophysics, 48(4), 326. http://dx.doi.org/10.3758/BF03206683

McBurney, D. H., Collings, V. B., \& Glanz, L. M. (1973). Temperature dependence of human taste responses. Physiology \& Behavior, 11, 89. http://dx.doi.org/10.1016/0031-9384(73)90127-3 
Meilgarrd, M. C., Civille, G. V., \& Carr, B. T. (2007). Sensory evaluation techniques (4th ed.). Boca Raton, FL: CRC Press Inc.

Moskowitz, H. R. (1972). Effects of solution temperature on taste intensity in humans. Physiology \& Behavior, 10(2), 289-292. http://dx.doi.org/10.1016/0031-9384(73)90312-0

Pamghorn, R. M. (1961). Taste interrelationships. II. suprathreshold solutions of sucrose and citric acid. Journal of Food Science, 26, 648. http://dx.doi.org/10.1111/j.1365-2621.1961.tb00811.x

Panghorn, R. M. (1962). Taste interrelationships III. suprathreshold solutions of sucrose and sodium chloride. Journal of Food Science, 27, 495.

Panghorn, R. M., \& Chrisp, R. B. (1964). Taste interrelationships VI. sucrose, sodium chloride and citric acid in canned tomato juice. Journal of Food Science, 29, 726.

Panghorn, R. M., Chrisp, R. B., \& Bertolero, L. L. (1970). Gustatory, salivary, and oral thermal responses to solutions of sodium chloride at four temperatures. Perception \& Pyschophysics, 8(2), 69. http://dx.doi.org/10.3758/BF03210177

Panghorn, R. M., \& Trabue, I. M. (1964). Taste interrelationships V. sucrose, sodium chloride, and citric acid in lima bean puree. Journal of Food Science, 29, 233. http://dx.doi.org/10.1111/j.1365-2621.1964.tb01724.x

Panghorn, R. M., \& Trabue, I. M. (1967). Detection and apparent taste intensity of salt-acid mixtures in two media. Perception \& Pyschophysics, 2(11), 503. http://dx.doi.org/10.3758/BF03210255

Paulus, K., \& Reisch, A. M. (1980). The influence of temperature on the threshold values of primary tastes. Chemical Senses, 5(1), 11. http://dx.doi.org/10.1093/chemse/5.1.11

Powers, J. J., Howell, D. A., \& Vacinek, S. J. (1971). Effect of temperature on threshold values for citric acid, malic acid and quinine sulphate---energy of activation and extreme-value determination. Journal of the Science of Food and Agriculture, 22, 543. http://dx.doi.org/10.1002/jsfa.2740221012

Schifferstein, H. N., \& Frijters, J. E. (1990). Sensory integration in citric acid/sucrose mixtures. Chemical Senses, 15(1), 87. http://dx.doi.org/10.1093/chemse/15.1.87

Schifferstein, H. N., \& Frijters, J. E. (1991). The effectiveness of different sweeteners in suppressing citric acid sourness. Perception \& Pyschophysics, 49, 1-9. http://dx.doi.org/10.3758/BF03211610

Schiffman, S. S., Sattely-Miller, E. A., Graham, B. G., Bennett, J. L., Booth, B. J., \& Desai, N. (2000). Effect of temperature, $\mathrm{pH}$, and ions on sweet taste. Physiology \& Behavior, 68, 469. http://dx.doi.org/10.1016/S0031-9384(99)00205-X

Talavera, K., Yasumatsu, K., Voets, T., Droogmans, G., Shigemura, N., \& Ninomiya, Y. (2005). Heat activation of TRPM5 underlies thermal sensitivity of sweet taste. Nature, 438, 1022. http://dx.doi.org/10.1038/nature04248.

Wheeler, J. B., Hoersch, H. M., Mahy, H. P., \& Kleinberg, A. S. (Eds.). (1981). Guide-lines for the selection and training of sensory panel members, ASTM STP 758. Philadelphia, PA: American Society for Testing and Materials.

Wise, P. M., \& Breslin, P. A. S. (2011). Relationship among taste qualities assessed with response-context effects. Chemical Senses, 36, 581. http://dx.doi.org/10.1093/chemse/bjr024

\section{Copyrights}

Copyright for this article is retained by the author(s), with first publication rights granted to the journal.

This is an open-access article distributed under the terms and conditions of the Creative Commons Attribution license (http://creativecommons.org/licenses/by/3.0/). 